\title{
No evidence for negative impacts of acute sulfoxaflor exposure on bee olfactory conditioning or working memory
}

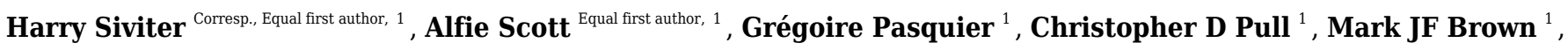 \\ Ellouise Leadbeater ${ }^{1}$ \\ ${ }^{1}$ School of Biological Sciences, Royal Holloway, University of London, Egham, UK \\ Corresponding Author: Harry Siviter \\ Email address: harry.siviter.2016@live.rhul.ac.uk
}

Systemic insecticides such as neonicotinoids and sulfoximines can be present in the nectar and pollen of treated crops, through which foraging bees can become acutely exposed. Research has shown that acute, field realistic dosages of neonicotinoids can negatively influence bee learning and memory abilities, with potential consequences for bee behaviour. As legislative reassessment of neonicotinoid use occurs globally, there is an urgent need to understand the potential risk of other systemic insecticides. Sulfoxaflor, the first branded sulfoximine-based insecticide, has the same mode of action as neonicotinoids, and may potentially replace them over large geographical ranges. Here we assessed the impact of acute sulfoxaflor exposure on performance in two paradigms that have previously been used to illustrate negative impacts of neonicotinoid pesticides on bee learning and memory. We assayed whether acute sulfoxaflor exposure influences (a) olfactory conditioning performance in both bumblebees (Bombus terrestris) and honeybees (Apis mellifera), using a proboscis extension reflex assay, and (b) working memory performance of bumblebees, using a radial-arm maze. We found no evidence to suggest that sulfoxaflor influenced performance in either paradigm. Our results suggest that despite a shared mode of action between sulfoxaflor and neonicotinoid-based insecticides, widely-documented effects of neonicotinoids on bee cognition may not be observed with sulfoxaflor, at least at acute exposure regimes. 
1

2

3

4

5

6

7 No evidence for negative impacts of acute sulfoxaflor exposure on bee olfactory conditioning or

8 working memory

9 Harry Siviter ${ }^{*+1}$, Alfie Scott ${ }^{\dagger 1}$, Grégoire Pasquier ${ }^{1}$, Christopher D Pull ${ }^{1}$, Mark J F Brown ${ }^{1}$ \& Ellouise

10 Leadbeater $^{1}$

11

12

13

14

15

16

17

18

19

20

21

$22 *$ Corresponding author:

23 Harry Siviter

24 School of Biological Sciences

25 Royal Holloway University of London

26 Egham, Surrey, TW20 OEX, UK

27 Harry.Siviter.2016@live.rhul.ac.uk 
Abstract

Systemic insecticides such as neonicotinoids and sulfoximines can be present in the nectar and pollen of treated crops, through which foraging bees can become acutely exposed. Research has shown that acute, field realistic dosages of neonicotinoids can negatively influence bee learning and memory abilities, with potential consequences for bee behaviour. As legislative reassessment of neonicotinoid use occurs globally, there is an urgent need to understand the potential risk of other systemic insecticides. Sulfoxaflor, the first branded sulfoximine-based insecticide, has the same mode of action as neonicotinoids, and may potentially replace them over large geographical ranges. Here we assessed the impact of acute sulfoxaflor exposure on performance in two paradigms that have previously been used to illustrate negative impacts of neonicotinoid pesticides on bee learning and memory. We assayed whether acute sulfoxaflor exposure influences (a) olfactory conditioning performance in both bumblebees (Bombus terrestris) and honeybees (Apis mellifera), using a proboscis extension reflex assay, and (b) working memory performance of bumblebees, using a radial-arm maze. We found no evidence to suggest that sulfoxaflor influenced performance in either paradigm. Our results suggest that despite a shared mode of action between sulfoxaflor and neonicotinoid-based insecticides, widelydocumented effects of neonicotinoids on bee cognition may not be observed with sulfoxaflor, at least at acute exposure regimes. 
54

55

56

57

\section{Introduction}

Bees provide vital pollination services for both wild flowers and commercial crops (Rader et al. 2016; Fijen et al. 2018), so localised declines in domestic honey bee populations and both localised and global range reductions of certain bumblebee species have led to suggestions that a global pollination crisis could be imminent (Biesmeijer et al. 2006; Colla \& Packer 2008; Aizen \& Harder 2009; Williams \& Osborne 2009; Potts et al. 2010; Cameron et al. 2011; Kerr et al. 2015; Goulson et al. 2015). Although the intensification of agriculture, habitat loss, global warming and pathogen exposure have all been linked with bee declines (Brown \& Paxton 2009; Winfree et al. 2009; Cameron et al. 2011; Kerr et al. 2015; Goulson et al. 2015; Samuelson et al. 2018), particular attention has focused on the impact of agrochemicals. A key focus of research has been to understand the impact of neonicotinoid-based insecticides on bees (Whitehorn et al. 2012; Godfray et al. 2014, 2015; Stanley et al. 2015a; Rundlöf et al. 2015; Goulson et al. 2015; Kessler et al. 2015; Woodcock et al. 2016, 2017; Baron, Raine \& Brown 2017b; Baron et al. 2017a; Tsvetkov et al. 2017; Main et al. 2018; Arce et al. 2018; Siviter et al. 2018b), leading to controversy worldwide and in some cases, legislative reassessment of their use. Sulfoximinebased insecticides, which share a mode of action with neonicotinoids as selective agonists of Nicotinic Acetyl Choline Receptors (NAChRs) (Zhu et al. 2011; Sparks et al. 2013), are a more recent entry to the insecticide market, and are currently approved for use in 81 countries around the world. In a recent horizon-scanning exercise involving 72 pollination biologists, sulfoximines were highlighted as an emerging potential threat to pollinators, based on a lack of knowledge regarding their sub-lethal effects (Brown et al. 2016).

Sulfoxaflor, the first branded sulfoximine-based insecticide, can negatively impact bumblebee colony fitness, reducing worker production and subsequent reproductive output (Siviter, Brown \& Leadbeater 2018a), with the effects comparable to those observed with neonicotinoids (Whitehorn et al. 2012; Rundlöf et al. 2015). A plethora of research on neonicotinoids has linked small sub-lethal effects on bee behaviour at the individual level to major impacts at the colony level, with neonicotinoid exposure influencing bee foraging success and motivation, (Gill, Ramos-Rodriguez \& Raine 2012; Feltham, Park \& Goulson 2014; Gill \& Raine 2014; Arce et al. 2017; Lämsä et al. 2018; Muth \& Leonard 2019), homing success (Henry et al. 2012; Fischer et al. 2014), brood care and thermoregulation (Crall et al. 2018). One way in particular that neonicotinoids may influence bee behaviour is through impacts on bee cognition, with a recent meta-analysis confirming detrimental effects of insecticide exposure on learning and memory at acute and field realistic regimes (Siviter et al. 2018b). As a systemic insecticide, sulfoxaflor, 
86

like neonicotinoids, can be present in the nectar and pollen of plants following treatment, meaning that foraging bees may be exposed either via the crop itself or through flowering weeds present in fields or orchards during spray (Botias et al. 2015; Kyriakopoulou et al. 2017). However, despite the similarity in mode of action between sulfoxaflor and neonicotinoids, the potential impact of sulfoxaflor exposure on bee learning and memory has not been tested.

In this study, we assay the impact of acute sulfoxaflor exposure on learning and memory in bees based on two paradigms through which previous authors have identified adverse effects of neonicotinoid exposure: a Proboscis Extension Reflex (PER) experiment (Stanley, Smith \& Raine 2015b; Siviter et al. 2018b) and a Radial Arm Maze-based assay (RAM;Samuelson et al. 2016). These paradigms are assays of (i) classical conditioning of olfactory stimuli and (ii) working memory (also known as short-term memory) respectively, and thus they may capture different aspects of foraging, although are unlikely to be mutually exclusive. For example, learning to discriminate between olfactory stimuli in a PER task may emulate learning to discriminate between rewarding and non-rewarding flower species, while RAM performance assays retention of short-term task-relevant information such as the location of flowers that a bee has recently visited (Foreman \& Ermakova 1998; Lihoreau, Chittka \& Raine 2010; Collett, Chittka \& Collett 2013; Samuelson et al. 2016). Exposure to certain neonicotinoids, and other nonneonicotinoid insecticides, has been shown to influence PER performance in both Apis and Bombus (Williamson, Baker \& Wright 2013; Stanley et al. 2015b; Piiroinen \& Goulson 2016; Siviter et al. 2018b), while impacts on RAM performance have only been tested in bumblebees (Samuelson et al. 2016). Given that sulfoxaflor and neonicotinoids, both act as agonists of nicotinic acetylcholine receptors (NAChRs) receptors (Sparks et al. 2013), we predicted that sulfoxaflor exposure would have similar negative impacts on PER performance in Apis and Bombus, and RAM performance for Bombus.

\section{Methods: PER- Experiment 1}

\section{Subjects and harnessing}

Five bumblebee (Bombus terrestris audax) colonies with approximately 150 workers were purchased (Koppert Ltd, Haverhill, UK) and moved into a wooden colony box $(28 \times 10 \times 18 \mathrm{~cm})$ connected to a flight arena $(100 \times 70 \times 50 \mathrm{~cm})$ that contained an ad libitum supply of sucrose solution ( $50^{\circ}$ Brix) and pollen. Only individuals that had been observed foraging on the feeder within the flight arena were subsequently used in the experiment (Martin, Fountain \& Brown 2018). Previous studies suggest that 
117 bumblebees are more responsive when starved for a period of time (Stanley et al. 2015b), and

118 consequently prior to all PER experiments involving bumblebees, we collected and harnessed all

119 potential subjects before leaving them overnight, and tested them the following morning.

120 Returning foraging honey bees (Apis mellifera) were collected from the entrance of five hives from a

121 research apiary at Royal Holloway University of London. Honeybee mortality is high when individuals are

122 harnessed for a sustained period of time, and as a result we collected and harnessed honeybees in the 123 same day, leaving them for one hour after harnessing, before randomly assigning them to a treatment

124 group (see below) and conducting the experiment. Bumblebees and honeybees were tested on different

125 days, and on any single test day, sixteen to forty bumblebees and honeybees were collected and

126 harnessed.

127

128

129

130

131

132

133

134

135

136

137

138

139

140

141

142

143

144

145

146

\section{Insecticide exposure}

Sulfoxaflor has been developed for a range of different crops, including as a seed treatment for bee attractive crops, but its most common application is currently as a foliar spray (Centner, Brewer \& Leal 2018). Foliar spray applications result in short-term bursts of high insecticide residues in the nectar of sprayed crops (United States Environmental Protection Agency 2016) and any concurrently flowering weeds. We thus based our estimates for acute exposure on data for the residue levels found in honeybee-collected nectar of cotton sprayed with sulfoxaflor from an Environmental Protection Agency (EPA) study, which demonstrated that over an 11 day period nectar concentrations ranged from 5.4146.97 ppb (United States Environmental Protection Agency 2016; application rate: 0.045 pounds (0.020 $\mathrm{kg}$ ) of active ingredient per acre, applied twice). We derived our sulfoxaflor treatments from a stock solution of $1 \mathrm{~g} \mathrm{dm}^{-3}$ sulfoxaflor (Greyhound Chromatography and Allied Chemicals) in acetone, which was combined with sucrose solution ( $50^{\circ}$ Brix) to make three treatment groups: $2.4 \mu \mathrm{g} \mathrm{dm}{ }^{-3}(2.4 \mathrm{ppb}), 10$ $\mu \mathrm{g} \mathrm{dm^{-3 }}$ (10ppb), $250 \mu \mathrm{g} \mathrm{dm}^{-3}$ (250ppb; positive control) and the negative control (sucrose with acetone only). Before training, we placed each bee horizontally (held in place with modelling clay) and pipetted a $10 \mu \mathrm{l}$ droplet of sucrose solution containing the randomly-assigned treatment solution onto a plastic surface, from which the bees could feed. Bees that did not immediately drink were encouraged to extend their proboscis by antennal stimulation with sucrose. Bees that did not consume the full quantity of sucrose solution were not used in the experiment (excluded bumblebees $\mathrm{N}=55, \mathrm{control}=13,2.4 \mathrm{ppb}$ $=16,10 p p b=16,250 p p b=10$; honeybees $N=17$, control $=2,2.4 p p b=6,10 p p b=5,250 p p b=4)$. After feeding, the bees were placed upright and left for an hour (Stanley et al. 2015b). 
147

148

149

150

151

152

153

154

155

156

157

158

159

160

161

162

163

164

165

166

167

168

169

170

171

172

173

174

175

176

177

\section{Training protocol}

We used an absolute conditioning proboscis extension reflex (PER) procedure in which lavender scent (conditioned stimulus; CS) was forward paired with antennal stimulation by sucrose solution (unconditioned stimulus; US; $50^{\circ}$ Brix). The subjects were placed $3 \mathrm{~cm}$ away from the odour tube that contained filter paper soaked in $4 \mu \mathrm{l}$ of the lavender essential oil. A programmable logic controller computer was used to blow a constant stream of air containing the odours towards the subjects from the odour tube. The odour tube was replaced every 20-30 trials to ensure that the odour was consistently strong throughout conditioning. Bees were exposed to 5 seconds of clean airflow (no odour), followed by 10 seconds of the odour. Six seconds after the start of odour exposure, the subject was presented with $0.8 \mu \mathrm{l}$ of untreated sucrose solution ( $50^{\circ}$ Brix) from a syringe. A positive response was recorded if the bee extended its proboscis in the first six seconds of odour presentation, before antennal stimulation with the US, and was always rewarded by immediate delivery of the sucrose solution. In the event of a negative response, we additionally recorded whether the bee responded to the antennal stimulation (to ascertain that the subject was motivated to extend its proboscis). Each subject received fifteen trials with an inter-trial interval of approximately 12 minutes. To ensure that the bees were learning about the odour and not other aspects of the experimental protocol, three nonscented probe trials were randomly distributed between the $5^{\text {th }}$ and $15^{\text {th }}$ learning trials. Bees that responded to the unscented stimulus in any probe trial were not included in the analysis (excluded bumblebees $n=10$; honeybees $n=1$ ). Each animal thus received 18 trials in total ( 15 test trials and 3 probe trials).

Medium- and long-term memory tests, whereby the subjects were presented with the conditioned odour in isolation for a single trial, were conducted with the same subjects 3 hours and 24 hours after the last learning trials, respectively. Once the experiment was finished, bees were frozen and their size recorded by measuring thorax width with electronic callipers (Mitutoyo), three times, from which a mean value was taken. We recorded size because it may influence the rate at which the insecticide is absorbed; larger bees empty their gut at a faster rate (Fournier et al. 2014) and previous studies have correspondingly found size-dependent effects of acute insecticide exposure on cognition (Samuelson et al. 2016).

In total, we tested 240 bumblebees and 174 honeybees. Bees that did not extend their proboscis in response to antennal sucrose stimulation in at least 5 learning trials were not used (bumblebee $\mathrm{N}=64$, control $=17,2.4 p p b=14,10 p p b=16,250 p p b=17$; honeybee $N=6$, control $=1,2.4 p p b=1,10 p p b=2$, 
$178250 \mathrm{ppb}=1$ ). A further 3 bumblebees were removed from the experiment because they extended their

179 proboscis before the odour was presented. Five bumblebees died, as did 46 honeybees. One bumblebee 180 was harnessed poorly and thus not included, as were 10 honeybees. This resulted in final sample sizes of 181102 bumblebees and 94 honeybees (bumblebees: control $=23,2.4 p p b=26,10 p p b=24,250 p p b=29$ :

182 honeybees: control $=29,2.4 \mathrm{ppb}=22,10 \mathrm{ppb}=22,250 \mathrm{ppb}=21$ ).

\section{Statistical analysis}

184 We followed an information theoretic model selection approach. The initial model set included a full 185 model and all subsets, including a null model that contained solely the intercept and "Colony" as a 186 random factor. We selected a 95\% confidence set of models based on Akaike weights derived from AICc values. In cases where the $95 \%$ confidence set contained more than one model, the models were averaged (Burnham \& Anderson 2002) (including the null if it was included within the confidence set) to produce parameter estimates and $95 \%$ confidence intervals. Data collected for bumblebees and honeybees were analysed separately due to potential differences between the species (see Siviter et al. 2018b).

Following (Stanley et al. 2015b), we analysed three dependent variables to identify sulfoxaflor effects on PER performance: (i) whether the bee responded to the CS in the absence of antennal stimulation (hereafter: "positive response") in at least one trial overall (ii) the total number of positive responses (hereafter learning level) from bees that learnt the association, and (iii) the trial that the bee first exhibited a positive response. We used generalised linear mixed effect models with binomial or poisson error structures, or mixed effect Cox models, respectively, where treatment, bee size and their interaction were specified as fixed factors, and colony as a random factor (see tables S1 \& S2). For medium- and long-term memory, we analysed whether or not the bee exhibited a positive response to the CS following the same method (binomial error structure). We used the packages, Ime4 (Bates et al. 2015), MuMin (Barton 2016), Coxme (Therneau 2018), Hmisc (Harrell \& Dupont 2018) and pscl (Jackman 202 2017).

\section{Methods: RAM- Experiment 2}

Subjects 
207 box ( $28 \times 16 \times 10.5 \mathrm{~cm}$, with a central divider that allowed access between compartments). When

208 transferring bees into the nest box individual bees were tagged with unique number disks, allowing the 209 identification of individuals. The nest box was attached to the radial arm maze (RAM; description 210 below), with access controlled using sliding trap-doors. When the bees were not being tested, gravity

211 feeders were placed in the RAM with an Ad libitum supply of $43^{\circ}$ Brix sucrose solution. Colonies were 212 provided with approximately 7 grams of pollen in the nest box 3 times a week. Colonies were used in 213 succession rather than simultaneously, and newly emerged bees were tagged daily throughout the 214 experiment.

\section{Radial arm maze}

A radial arm maze classically consists of 8 arms, each of which contains a hidden food reward (Foreman \& Ermakova 1998). Animals forage within the maze and search for the food rewards, whilst avoiding revisiting arms that they have already depleted, and Samuelson et al. (2016) have previously confirmed that bumblebees use working memory to minimize such revisits. We based our design on the set-up used by Samuelson et al. (2016) but modified their original vertical design to create a horizontal version. The aim of this modification was to reduce reliance on learnt movement rules by forcing subjects to return to the centre of the maze between choices, as is usually the case for rodent versions of the RAM (Olton \& Samuelson 1976; Foreman \& Ermakova 1998). Our horizontal maze was constructed from acrylic plastic, sealed together with non-toxic grey silicone (Bondit). Each of the 8 arms contained a removable platform $(7.2 \times 2.6 \times 0.5 \mathrm{~mm})$ upon which the bees could land to access a small hole in the wall. By extending the proboscis through this hole, bees could access a sucrose reward ( $\left.43^{\circ} \mathrm{Brix}\right)$ that was not visible from the platform (volume varied between stages; see below). After visitation, the platform could be rapidly replaced with a clean alternative to prevent the use of scent marks to identify visited arms. The availability of visual global landmarks (often a view of the laboratory) has been shown to contribute to performance in a RAM for rodents and other animals (Foreman \& Ermakova 1998;

Wilkinson, Chan \& Hall 2007), but a) our laboratory regularly changes in appearance and b) light control was important for our video software. Thus, our maze walls were opaque, but papered with a black and white panoramic photo of the laboratory to allow bees to orientate.

\section{Stage 1- Group training}

The objective of this stage was to identify motivated foragers. Each morning before testing, the RAM was set up with $10 \mu \mathrm{l} 43^{\circ}$ Brix sucrose solution on each landing platform. All bees were then allowed into 
238 the RAM to forage on the landing platforms (platforms were continuously reloaded with sucrose

solution when drained). Only bees that were observed foraging within the maze at this stage (by inserting the proboscis into the holes at the end of each arm) proceeded to Stage 2 (Individual training).

\section{Stage 2 - Individual training}

The objective of the individual training stage was for bees to learn the win-shift nature of the RAM task, over the course of 10 training bouts. During each bout, bees were required to visit all 8 artificial platforms and then return to the nest box to empty their crop. At the outset of each bout, each platform contained $10 \mu \mathrm{l}$ of sucrose solution ( $20 \mu \mathrm{l}$ for the first bout, to increase motivation). Rewards were not refilled after visitation, but landing platforms were replaced with identical but clean replacements. Once the bee found the final reward, we increased the amount of sucrose solution in that arm (from outside the maze) so that the bee's crop was full, encouraging her to return to the nest box. Choices in the RAM were recorded as either: Correct - feeding from platforms that had not yet been visited, or Incorrectattempting to feed from platforms that had already been depleted.

If a bee attempted to return to the nest box 3 times prior to visiting all landing platforms, or if the trial exceeded 20 minutes, the bee was permitted to return to the nest box. As with Samuelson et al. (2016), each bee completed 10 training bouts.

Stage 3-Pesticide exposure

Our pesticide exposure regime differed from that used in the PER regime because our RAM experiment was designed to allow direct comparison with the results described by Samuelson et al 2016, for thiamethoxam. Samuelson et al (2016) aimed to mimic the dosage received during one hour of foraging for nectar, whilst overcoming the problem that feeding on a large volume of sucrose may reduce a bee's motivation to participate in the RAM. To that end, bees were only fed half of the volume of nectar that would normally be consumed during such a foraging bout $(0.5 \times 37.7 \mathrm{mg})$, with a doubled concentration of sulfoxaflor. To allow for direct comparison, we followed the same approach here (and bumblebees thus received a higher dosage than those in the PER treatment groups described above). Each test subject was intercepted as it was returning to the RAM after emptying its crop following the 10th training bout. They were placed into a plastic beaker, and fed $18.85 \mu \mathrm{l}$ of sucrose solution from the randomly assigned treatment group. We included four treatment groups, intended to mimic foraging on crops with nectar containing either $0 \mathrm{ppb}$ (control), $5 \mu \mathrm{g} \mathrm{dm}{ }^{-3}(5 \mathrm{ppb}), 10 \mu \mathrm{g} \mathrm{dm} \mathrm{m}^{-3}(10 \mathrm{ppb})$ or $250 \mu \mathrm{g} \mathrm{dm}$ 
267 (250ppb or positive control) of sulfoxaflor, with bees from each treatment groups receiving 0, 0.045,

$2680.091 \& 2.5 \mathrm{ng}$ respectively. After consumption, the bees were held in the plastic beaker for 45 minutes

269 before being returned to the nest (Samuelson et al. 2016). 60 bees were originally trained on the RAM

270 but 2 failed to re-commence foraging after the exposure stage ( $N$ values, control $=14,5 p p b=15,10 p p b$

$271=15,250 \mathrm{ppb} \mathrm{n}=14)$.

272 Stage 4- Test trial

273 Following exposure, the bees were presented with the exact set up they had experienced in the training

274 phase of the experiment (phase 2) and tested one final time. After completing the task bees were

275 collected and frozen and, at a later date, we measured their thorax width.

276

277 Statistical Analysis

278 As with experiment 1, we used an information theoretic model selection approach when analysing each

279 dependent variable and, as in previous work (Olton \& Samuelson 1976; Foreman \& Ermakova 1998;

280 Samuelson et al. 2016), three different measures were chosen to assess performance; (i) total revisits to

281 platforms which have been previously visited, (ii) the number of correct choices made before making a

282 revisit and (iii) the proportion of correct choices in the first 8 visits. For all dependent variables,

283 treatment, bee size and the interaction between them were included as fixed factors with colony

284 included as a random factor. To account for overdispersion, we used a generalised linear model with a

285 negative binomial distribution error structure (g/m.nb) to analyse total revisits, and a generalised linear

286 model $(\mathrm{glm})$ with a poisson distributed error structure to analyse the number of correct choices in the

287 first 8 visits. A mixed effect cox model (coxme) was used to analyse correct choices before first revisit.

288 All analyses were conducted in R studio (version 1.1.419) using the R packages Ime4 (Bates et al. 2015),

289 MuMin (Barton 2016), Coxme (Therneau 2018), AER (Kleiber \& Zeileis 2008), MASS (Ripley \& Venables

290 2002), Hmisc (Harrell \& Dupont 2018).

291 Results: PER - Experiment 1

292 For our first measure of learning (production of at least one conditioned response to the stimulus), we

293 found no evidence that acute sulfoxaflor exposure influenced bumblebees (Figure 1A, glmer, 2.4 ppb

294 parameter estimate $(\mathrm{PE})=-0.00,95 \%$ confidence intervals $(\mathrm{Cl})=-0.34$ to $0.33 ; 10 \mathrm{ppb} \mathrm{PE}=0.00,95 \% \mathrm{Cl}=$

$295-0.35$ to $0.36 ; 250 \mathrm{ppb} P E=0.05,95 \% \mathrm{Cl}=-0.43$ to 0.53 ) or honeybees (Figure $2 \mathrm{~A}$; glmer, $2.4 \mathrm{ppb} \mathrm{PE}=-$

$2961.30,95 \% \mathrm{Cl}=-14.19$ to $11.60 ; 10 \mathrm{ppb} \mathrm{PE}=-1.26,95 \% \mathrm{Cl}=-14.82$ to $12.31 ; 250 \mathrm{ppb} \mathrm{PE}=-7.32,95 \% \mathrm{Cl}=$

Peer] reviewing PDF | (2019:03:35822:1:2:NEW 24 May 2019) 
297

298

299

300

301

302

303

304

305

306

307

308

309

310

311

312

313

314

315

316

317

318

319

320

321

322

323

324

325

326

-53.10 to 38.45 ). Learning level (number of positive responses) was also not influenced by sulfoxaflor exposure (bumblebees, Figure 1B; glmer; wi (treatment) = 0.017; honeybees, Figure 2B; glmer, 2.4 ppb $\mathrm{PE}=1.18,95 \% \mathrm{Cl}=-8.23$ to $10.59 ; 10 \mathrm{ppb} \mathrm{PE}=1.05,95 \% \mathrm{Cl}=-6.93$ to $9.04 ; 250 \mathrm{ppb} \mathrm{PE}=0.31,95 \% \mathrm{Cl}=-$ 4.11 to 4.72 ). Finally, there was no evidence to suggest that sulfoxaflor exposure influenced the speed at which either bumblebees or honeybees learnt the olfactory association (bumblebees, Figure 1C, coxme, $2.4 \mathrm{ppb} P \mathrm{PE}=-0.00,95 \% \mathrm{Cl}=-0.93$ to $0.78 ; 10 \mathrm{ppb} \mathrm{PE}=-0.00,95 \% \mathrm{Cl}=-0.91$ to $0.87 ; 250 \mathrm{ppb} \mathrm{PE}=0.03$, $95 \% \mathrm{Cl}=-0.39$ to 1.22 ; honeybees, Figure $2 \mathrm{C}$; coxme, $2.4 \mathrm{ppb} \mathrm{PE}=-0.11,95 \% \mathrm{Cl}=-0.72$ to 0.51 ; coxme, $10 \mathrm{ppb} P \mathrm{PE}=-0.02,95 \% \mathrm{Cl}=-0.34$ to 0.29 ; coxme, $250 \mathrm{ppb} \mathrm{PE}=-0.01,95 \% \mathrm{Cl}=-0.30$ to 0.28 ), suggesting no influence of acute sulfoxaflor exposure on olfactory conditioning performance in either species.

Similarly, there was no impact of sulfoxaflor exposure on either bumblebee or honeybee memory at 3 hours after training (bumblebee; Figure $3 \mathrm{~A}$; glmer, $2.4 \mathrm{ppb} \mathrm{PE}=0.02,95 \% \mathrm{Cl}=-0.59$ to $0.63 ; 10 \mathrm{ppb} \mathrm{PE}=$ $-0.07,95 \% \mathrm{Cl}=-0.98$ to $0.83 ; 250 \mathrm{ppb} \mathrm{PE}=0.06,95 \% \mathrm{Cl}=-0.62$ to 0.75 ; honeybee; Figure $3 \mathrm{C}$; wi (treatment) $=0.033$ ) or at 24 hours after training (bumblebee; Figure 3B; wi (treatment) $=0.042$; honeybee ; Figure 3D; glmer, $2.4 \mathrm{ppb} P E=-0.39,95 \% \mathrm{Cl}=-1.79$ to $1.02 ; 10 \mathrm{ppb} \mathrm{PE}=-0.36,95 \% \mathrm{Cl}=-1.66$ to $0.94 ; 250 \mathrm{ppb} P E=0.04,95 \% \mathrm{Cl}=-0.79$ to 0.88 ).

\section{Results: RAM - experiment 2}

We found no statistical support for an effect of sulfoxaflor exposure on total revisits (Figure 4A; glm.nb, $5 p p b$ treatment $\mathrm{PE}=0.24,95 \% \mathrm{Cl}=-0.56$ to $1.05 ; 10 \mathrm{ppb} \mathrm{PE}=0.16,95 \% \mathrm{Cl}=-0.46$ to $0.79 ; 250 \mathrm{ppb} \mathrm{PE}=$ $0.23,95 \% \mathrm{Cl}=-0.55$ to 1 ) or on the proportion of correct choices in the first 8 visits of bumblebees following sulfoxaflor exposure (Figure 4B glm, (wi (treatment) $=0.038)$. Similarly, we found no statistically significant effect of sulfoxaflor exposure on the number of correct choices before the first revisit (Figure 5; coxme, $5 \mathrm{ppb} \mathrm{PE}=0.55,95 \% \mathrm{Cl}=-0.54$ to $1.64 ; 10 \mathrm{ppb} \mathrm{PE}=0.25,95 \% \mathrm{Cl}=-0.48$ to 0.98 ; $250 \mathrm{ppb} P E=0.49,95 \% \mathrm{Cl}=-0.52$ to 1.51 ), suggesting no impact of acute sulfoxaflor exposure on bumblebee working memory. Further analysis also suggested no impact on bee behaviour (see supplementary material).

\section{Discussion}

We found no evidence to suggest that acute sulfoxaflor exposure influenced bumblebee or honeybee olfactory conditioning or bumblebee working memory, even at the highest concentrations of exposure tested (250ppb). Given the range of dosages we tested, which included positive controls that far exceeded levels likely to be found in the field, it is unlikely that acute sulfoxaflor exposure in adult bees 
327 will influence cognition after environmental exposure, at least with regard to olfactory conditioning and 328 working memory performance.

We used two experimental paradigms investigating the impact of acute sulfoxaflor exposure on bee learning and memory. Although a wide variety of different paradigms can be used to assess bee cognition (Bernadou et al. 2009; Zhang \& Nieh 2015; Lämsä et al. 2018) we chose to use both PER and the RAM, in combination, as these paradigms allow us to consider the impact of sulfoxaflor exposure on working memory (also known as short-term memory), medium-term and long-term memory (Menzel 2012). Interestingly, in both of these paradigms, the neonicotinoid thiamethoxam, one of the three neonicotinoids insecticides banned from outdoor agricultural use within the European Union, has been shown to influence performance at comparable dosages (Stanley et al. 2015b; Samuelson et al. 2016). Both neonicotinoids and sulfoximine-based insecticide share the same mode of action, acting as selective agonists of Nicotinic Acetyl Choline Receptors (NAChRs) (Zhu et al. 2011; Sparks et al. 2013). Acute neonicotinoid exposure can inactivate the mushroom bodies of bee brains (Palmer et al. 2013), which are essential for learning and memory in bees (Menzel 2012). The effects of sulfoxaflor exposure on bee neurology have not been explored, but could provide useful information in understanding why neonicotinoids, but not sulfoximine-based insecticides, influence bee cognition, at least under these experimental paradigms and dosages. Ultimately, sulfoxaflor could be used as a reference substance to understand why some insecticides, which act on nicotinic acetyl choline receptors (NAChRs) have a negative impact on bee cognition, while others do not.

We tested the impact of acute sulfoxaflor exposure (rather than chronic exposure) on bee learning and memory. A recent meta-analysis showed that chronic insecticide exposure can have larger effects on bee memory than acute exposure for adult bees, and so we cannot rule out that more prolonged exposure would have identified an effect of sulfoxaflor exposure. However, an acute dosage potentially mimics the exposure regime of a foraging adult bee in the field more closely, because individuals may forage on a range of different crops and flowers in addition to the treated crop, over an extended period of time. Chronic exposure is nonetheless clearly relevant for larval brood, and the same meta-analysis highlighted that exposure as a larva is more likely to have a negative impact on bee learning than adult exposure (Siviter et al. 2018b). Larval exposure to thiamethoxam has been shown to influence synaptic density in the mushroom bodies of bee brains (Peng \& Yang 2016) and increase neural vulnerability to mitochondrial dysfunction (Moffat et al. 2015), which may be linked to documented effects of exposure 
359

360

361

362

363

364

365

366

367

368

369

370

371

372

373

374

375

376

377

378

379

380

381

382

383

384

385

386

387

388

389

390

on cognitive function (Klein et al. 2017). Thus, although our results show no effect of acute sulfoxaflor exposure on bumblebee or honeybee cognition, further research needs to be conducted to understand the potential impact of chronic exposure, both in adults and larvae. Furthermore, given the dearth of data on non-Apis/Bombus bees (Siviter et al. 2018b), researchers should prioritise assessing the impact of sulfoxaflor on non-social bees.

The hypothesis that negative effects of neonicotinoid exposure on bees are mediated in part by the widely-documented sub-lethal effects on learning and memory described above, which may impact upon bee foraging behaviour and thus potentially colony productivity, has received much attention (Klein et al. 2017; Siviter et al. 2018b). However, neonicotinoid insecticides have many other sub-lethal effects on bee behaviour and physiology (Wu et al. 2012; Laycock et al. 2012; Baron et al. 2017b; a; Crall et al. 2018) and any causal link between reduced cognitive performance and foraging efficiency remains to be established, because data linking bee cognitive traits and foraging efficiency are difficult to collect. The evidence that does exist is contradictory. Raine \& Chittka (2008) found a positive association between the nectar collection rate of workers allowed to forage outdoors, and the visual learning performance of their sisters from the same colony, but Evans, Smith \& Raine (2017) found no correlation between individual visual learning performance and nectar collection rate. A better understanding of the relationship between bee cognitive traits and foraging efficiency is clearly important if we are to identify and mitigate against the sub-lethal impacts that underlie negative impacts of neonicotinoid insecticide exposure on bumblebee colony reproductive output (Whitehorn et al. 2012; Rundlöf et al. 2015; Woodcock et al. 2017). In contrast, our findings suggest that sub-lethal effects on learning and memory are unlikely to underlie the negative impacts of sulfoxaflor on colony reproductive output in bumblebees.

If memory and learning are unaffected by exposure, what other mechanisms might underlie the impact of sulfoxaflor on bumblebee colony fitness (Siviter et al. 2018a)? While previous work on impacts of neonicotinoids on learning and memory (Samuelson et al. 2016; Siviter et al. 2018b) inspired the work reported here, these insecticides have been demonstrated to produce a range of sublethal impacts, beyond cognitive effects. These include reductions in food intake, foraging motivation, thermoregulatory activity, nursing behaviour, ovary development, and egg laying (Laycock et al. 2012; Baron et al. 2017b; Lämsä et al. 2018; Crall et al. 2018). Impacts of sulfoxaflor on bumblebee colony fitness appear to be driven by reduced worker production at the early stage of colony development (Siviter et al. 2018a), but our results here suggest that this is unlikely to be due to impacts on worker 
391 learning or memory in food-related tasks. Consequently, we suggest that future work should focus on

392 examining potential sub-lethal impacts on ovary development and egg laying, which could directly relate 393 to reductions in worker production.

394

395

\section{Conclusions}

Sulfoximine-based insecticides are becoming globally important, with sulfoxaflor now registered for use in 81 countries, including a number of European Union member states (European Commission). Although mitigation measures can reduce the likelihood of pollinator exposure (Centner et al. 2018), uptake of such measures varies widely across legislative regimes. Previous work with neonicotinoids demonstrated the importance of understanding sub-lethal effects of insecticides on bee health. Here we find no evidence for an impact of acute sulfoxaflor exposure on bee olfactory conditioning or bumblebee working memory, despite the occurrence of such impacts when using the same protocols with neonicotinoid exposure. This suggests that the impacts of sub-lethal exposure in learning and memory are unlikely to be the mechanism behind impacts of sulfoxaflor on colony reproductive success (Siviter et al. 2018a). Further studies are needed to understand how, and under what conditions, sulfoxaflor may impact bee health. Such data will enable more informed regulatory and policy decisions on the future use of this insecticide in crops that attract bees.

408

Acknowledgments - We would like to thank Ash Samuelson and Callum Martin for offering methodological advice.

411

\section{Reference list}

413

Aizen, M.A. \& Harder, L.D. (2009) The global stock of domesticated honey bees is growing slower than agricultural demand for pollination. Current Biology, 19, 915-918.

Arce, A.N., David, T.I., Randall, E.L., Ramos Rodrigues, A., Colgan, T.J., Wurm, Y. \& Gill, R.J. (2017) Impact of controlled neonicotinoid exposure on bumblebees in a realistic field setting. Journal of Applied

Arce, A.N., Ramos Rodrigues, A., Yu, J., Colgan, T.J., Wurm, Y. \& Gill, R.J. (2018) Foraging bumblebees acquire a preference for neonicotinoid-treated food with prolonged exposure. Proceedings of the Royal Society B: Biological Sciences, 285, 20180655.

Baron, G.L., Jansen, V.A.A., Brown, M.J.F. \& Raine, N.E. (2017a) Pesticide reduces bumblebee colony 
423

424

425

426

427

428

429

430

431

432

433

434

435

436

437

438

439

440

441

442

443

444

445

446

447

448

449

450

451

452

453

454

initiation and increases probability of population extinction. Nature Ecology \& Evolution, 1, 13081316.

Baron, G.L., Raine, N.E. \& Brown, M.J.F. (2017b) General and species-specific impacts of a neonicotinoid insecticide on the ovary development and feeding of wild bumblebee queens. Proceedings of the Royal Society B: Biological Sciences, 284, 20170123.

Barton, K. (2016) MuMIn: Multi-Model Inference. R package version 1.15.6. URL https://cran.rproject.org/package=MuMIn

Bates, D., Mächler, M., Bolker, B. \& Walker, S. (2015) Fitting linear mixed-effects models using Ime4. Journal of Statistical Software, 67, 51.

Bernadou, A., Démares, F., Couret-Fauvel, T., Sandoz, J.C. \& Gauthier, M. (2009) Effect of fipronil on side-specific antennal tactile learning in the honeybee. Journal of Insect Physiology, 55, 1099-1106.

Biesmeijer, J.C., Roberts, S.P.M., Reemer, M., Ohlemüller, R., Edwards, M., Peeters, T., Schaffers, A.P., Potts, S.G., Kleukers, R., Thomas, C.D., Settele, J. \& Kunin, W.E. (2006) Parallel declines in pollinators and insect-pollinated plants in Britain and the Netherlands. Science, 313, 351-4.

Botias, C., David, A., Horwood, J., Abdul-sada, A., Nicholls, E., Hill, E. \& Goulson, D. (2015) Neonicotinoid residues in wild flowers, a potential route of chronic exposure for bees. Environmental Science and Technology, 49, 12731-12740.

Brown, M.J.F., Dicks, L. V, Paxton, R.J., Baldock, K.C.R., Barron, A.B., Chauzat, M.-P., Freitas, B.M., Goulson, D., Jepsen, S., Kremen, C., Li, J., Neumann, P., Pattemore, D.E., Potts, S.G., Schweiger, O., Seymour, C.L. \& Stout, J.C. (2016) A horizon scan of future threats and opportunities for pollinators and pollination. PeerJ, 4, e2249.

Brown, M.J.F. \& Paxton, R.J. (2009) The conservation of bees : a global perspective. Apidologie, 40, 410416.

Burnham, K.P. \& Anderson, D.R. (2002) Model Selection and Multimodel Inference: A Practical Information-Theoretic Approach (2nd Ed).

Cameron, S.A., Lozier, J.D., Strange, J.P., Koch, J.B., Cordes, N., Solter, L.F. \& Griswold, T.L. (2011) Patterns of widespread decline in North American bumble bees. Proceedings of the National Academy of Sciences, 108, 662-667.

Centner, T.J., Brewer, B. \& Leal, I. (2018) Reducing damages from sulfoxaflor use through mitigation measures to increase the protection of pollinator species. Land Use Policy, 75, 70-76.

Colla, S. \& Packer, L. (2008) Evidence for decline in eastern North American bumblebees (Hymenoptera: Apidae), with special focus on Bombus affinis Cresson. Biodiversity and Conservation, 17, 1379- 
455

456

457

458

459

460

461

462

463

464

465

466

467

468

469

470

471

472

473

474

475

476

477

478

479

480

481

482

483

484

485

486

1391.

Collett, M., Chittka, L. \& Collett, T.S. (2013) Spatial memory in insect navigation. Current Biology, 23, R789-R800.

Crall, J.D., Switzer, C.M., Oppenheimer, R.L., Ford Versypt, A.N., Dey, B., Brown, A., Eyster, M., Guérin, C., Pierce, N.E., Combes, S.A. \& de Bivort, B.L. (2018) Neonicotinoid exposure disrupts bumblebee nest behavior, social networks, and thermoregulation. Science, 362, 683-686.

European Commission. EU Pesticides database. URL http://ec.europa.eu/food/plant/pesticides/eupesticides-database/public/?event=activesubstance.detail\&language=EN\&selectedID=2282 [accessed 15 May 2018]

Evans, L.J., Smith, K.E. \& Raine, N.E. (2017) Fast learning in free-foraging bumble bees is negatively correlated with lifetime resource collection. Scientific Reports, 7, 496.

Feltham, H., Park, K. \& Goulson, D. (2014) Field realistic doses of pesticide imidacloprid reduce bumblebee pollen foraging efficiency. Ecotoxicology, 23, 317-323.

Fijen, T.P.M., Scheper, J.A., Boom, T.M., Janssen, N., Raemakers, I. \& Kleijn, D. (2018) Insect pollination is at least as important for marketable crop yield as plant quality in a seed crop (ed R Irwin). Ecology Letters, 21, 1704-1713.

Fischer, J., Müller, T., Spatz, A.-K., Greggers, U., Grünewald, B. \& Menzel, R. (2014) Neonicotinoids Interfere with Specific Components of Navigation in Honeybees (ed D Naug). PLoS ONE, 9, e91364.

Foreman, N. \& Ermakova, I. (1998) Handbook of Spatial Research Paradigms and Methodologies (eds N Foreman and R Gillett). Psychology Press.

Fournier, A., Rollin, O., Le Féon, V., Decourtye, A. \& Henry, M. (2014) Crop-Emptying Rate and the Design of Pesticide Risk Assessment Schemes in the Honey Bee and Wild Bees (Hymenoptera: Apidae). Journal of Economic Entomology, 107, 38-46.

Gill, R.J. \& Raine, N.E. (2014) Chronic impairment of bumblebee natural foraging behaviour induced by sublethal pesticide exposure. Functional Ecology, 28, 1459-1471.

Gill, R.J., Ramos-Rodriguez, O. \& Raine, N.E. (2012) Combined pesticide exposure severely affects individual- and colony-level traits in bees. Nature, 491, 105-8.

Godfray, H.C.J., Blacquiere, T., Field, L.M., Hails, R.S., Petrokofsky, G., Potts, S.G., Raine, N.E., Vanbergen, A.J. \& McLean, A.R. (2014) A restatement of the natural science evidence base concerning neonicotinoid insecticides and insect pollinators. Proceedings of the Royal Society B: Biological Sciences, 281, 20140558-20140558.

Godfray, H.C.J., Blacquière, T., Field, L.M., Hails, R.S., Potts, S.G., Raine, N.E., Vanbergen, A.J. \& McLean, 
487

488

489

490

491

492

493

494

495

496

497

498

499

500

501

502

503

504

505

506

507

508

509

510

511

512

513

514

515

516

517

518

A.R. (2015) A restatement of recent advances in the natural science evidence base concerning neonicotinoid insecticides and insect pollinators. Proceedings of the Royal Society B: Biological Sciences, 282, 20151821.

Goulson, D., Nicholls, E., Botias, C. \& Rotheray, E.L. (2015) Bee declines driven by combined stress from parasites, pesticides, and lack of flowers. Science, 347, 1255957.

Harrell, F.E. \& Dupont, C. (2018) Hmisc: Harrell miscellaneous. R package version 4.1-1. URL https://cran.r-project.org/package=Hmisc

Henry, M., Béguin, M., Requier, F., Rollin, O., Odoux, J., Aupinel, P., Aptel, J., Tchamitchian, S. \& Decourtye, A. (2012) A common pesticide decreases foraging success and survival in honey bees. Science, 336, 3-5.

Jackman, S. (2017) pscl: Classes and methods for R developed in the political science computational laboratory. URL https://github.com/atahk/pscl/

Kerr, J.T., Pindar, A., Galpern, P., Packer, L., Potts, S.G., Roberts, S.M., Rasmont, P., Schweiger, O., Colla, S.R., Richardson, L.L., Wagner, D.L., Gall, L.F., Sikes, D.S. \& Pantoja, A. (2015) Climate change impacts on bumblebees converge across continents. Science, 349, 177-180.

Kessler, S.C., Tiedeken, E.J., Simcock, K.L., Derveau, S., Mitchell, J., Softley, S., Radcliffe, A., Stout, J.C. \& Wright, G.A. (2015) Bees prefer foods containing neonicotinoid pesticides. Nature, 521, 74-76.

Kleiber, C. \& Zeileis, A. (2008) Applied Econometrics with R. Springer-Verlag, New York.

Klein, S., Cabirol, A., Devaud, J.-M., Barron, A.B. \& Lihoreau, M. (2017) Why bees are so vulnerable to environmental stressors. Trends in Ecology and Evolution, 32, 268-278.

Kyriakopoulou, K., Kandris, I., Pachiti, I., Kasiotis, K.M., Spyropoulou, A., Santourian, A., Kitromilidou, S., Pappa, G. \& Glossioti, M. (2017) Collection and analysis of pesticide residue data for pollen and nectar - Final Report. EFSA Supporting Publications, 14.

Lämsä, J., Kuusela, E., Tuomi, J., Juntunen, S. \& Watts, P.C. (2018) Low dose of neonicotinoid insecticide reduces foraging motivation of bumblebees. Proceedings of the Royal Society B: Biological Sciences, 285, 20180506.

Laycock, I., Lenthall, K.M., Barratt, A.T. \& Cresswell, J.E. (2012) Effects of imidacloprid, a neonicotinoid pesticide, on reproduction in worker bumble bees (Bombus terrestris). Ecotoxicology, 21, 19461946.

Lihoreau, M., Chittka, L. \& Raine, N.E. (2010) Travel optimization by foraging bumblebees through readjustments of traplines after discovery of new feeding locations. The American Naturalist, 176, $744-757$.

Peer] reviewing PDF | (2019:03:35822:1:2:NEW 24 May 2019) 
519 Main, A.R., Webb, E.B., Goyne, K.W. \& Mengel, D. (2018) Neonicotinoid insecticides negatively affect

520

521

522

523

524

525

526

527

528

529

530

531

532

533

534

535

536

537

538

539

540

541

542

543

544

545

546

547

548

549

550 performance measures of non-target terrestrial arthropods: a meta-analysis. Ecological Applications, 28, 1232-1244.

Martin, C.D., Fountain, M.T. \& Brown, M.J.F. (2018) Bumblebee olfactory learning affected by task allocation but not by a trypanosome parasite. Scientific Reports, 8, 5809.

Menzel, R. (2012) The honeybee as a model for understanding the basis of cognition. Nature Reviews Neuroscience, 13, 758-768.

Moffat, C., Pacheco, J.G., Sharp, S., Samson, A.J., Bollan, K.A., Huang, J., Buckland, S.T. \& Connolly, C.N. (2015) Chronic exposure to neonicotinoids increases neuronal vulnerability to mitochondrial dysfunction in the bumblebee (Bombus terrestris). FASEB Journal, 29, 2112-2119.

Muth, F. \& Leonard, A.S. (2019) A neonicotinoid pesticide impairs foraging, but not learning, in freeflying bumblebees. Scientific Reports, 9, 4764.

Olton, D.S. \& Samuelson, R.J. (1976) Remembrance of places passed: Spatial memory in rats. Journal of Experimental Psychology: Animal Behavior Processes, 2, 97-116.

Palmer, M.J., Moffat, C., Saranzewa, N., Harvey, J., Wright, G.A. \& Connolly, C.N. (2013) Cholinergic pesticides cause mushroom body neuronal inactivation in honeybees. Nature Communications, $\mathbf{4}$, 1634-1638.

Peng, Y. \& Yang, E. (2016) Sublethal dosage of imidacloprid reduces the microglomerular density of honey bee mushroom bodies. Scientific Reports, 6, 19298.

Piiroinen, S. \& Goulson, D. (2016) Chronic neonicotinoid pesticide exposure and parasite stress differentially affects learning in honeybees and bumblebees. Proceedings of the Royal Society B: Biological Sciences, 283, 20160246.

Potts, S.G., Roberts, S.P.M., Dean, R., Marris, G., Brown, M.A., Jones, R., Neumann, P. \& Settele, J. (2010) Declines of managed honey bees and beekeepers in Europe. Journal of Apicultural Research, 49, $15-22$.

Rader, R., Bartomeus, I., Garibaldi, L.A., Garratt, M.P.D., Howlett, B.G., Winfree, R., Cunningham, S.A., Mayfield, M.M., Arthur, A.D., Andersson, G.K.S., Bommarco, R., Brittain, C., Carvalheiro, L.G., Chacoff, N.P., Entling, M.H., Foully, B., Freitas, B.M., Gemmill-Herren, B., Ghazoul, J., Griffin, S.R., Gross, C.L., Herbertsson, L., Herzog, F., Hipólito, J., Jaggar, S., Jauker, F., Klein, A.-M., Kleijn, D., Krishnan, S., Lemos, C.Q., Lindström, S.A.M., Mandelik, Y., Monteiro, V.M., Nelson, W., Nilsson, L., Pattemore, D.E., de O. Pereira, N., Pisanty, G., Potts, S.G., Reemer, M., Rundlöf, M., Sheffield, C.S., Scheper, J., Schüepp, C., Smith, H.G., Stanley, D.A., Stout, J.C., Szentgyörgyi, H., Taki, H., Vergara, 
551

552

553

554

555

556

557

558

559

560

561

562

563

564

565

566

567

568

569

570

571

572

573

574

575

576

577

578

579

580

581

582

C.H., Viana, B.F. \& Woyciechowski, M. (2016) Non-bee insects are important contributors to global crop pollination. Proceedings of the National Academy of Sciences, 113, 146-151.

Raine, N.E. \& Chittka, L. (2008) The correlation of learning speed and natural foraging success in bumblebees. Proceedings of the Royal Society B: Biological Sciences, 275, 803-808.

Ripley, B.D. \& Venables, W.N. (2002) Modern Applied Statistics with S, Fourth edi. Springer, New York.

Rundlöf, M., Andersson, G.K.S., Bommarco, R., Fries, I., Hederström, V., Herbertsson, L., Jonsson, O., Klatt, B.K., Pedersen, T.R., Yourstone, J. \& Smith, H.G. (2015) Seed coating with a neonicotinoid insecticide negatively affects wild bees. Nature, 521, 77-80.

Samuelson, E.E.W., Chen-Wishart, Z.P., Gill, R.J. \& Leadbeater, E. (2016) Effect of acute pesticide exposure on bee spatial working memory using an analogue of the radial-arm maze. Scientific Reports, 6, 38957.

Samuelson, A.E., Gill, R.J., Brown, M.J.F. \& Leadbeater, E. (2018) Lower bumblebee colony reproductive success in agricultural compared with urban environments. Proceedings of the Royal Society B: Biological Sciences, 285, 20180807.

Siviter, H., Brown, M.J.F. \& Leadbeater, E. (2018a) Sulfoxaflor exposure reduces bumblebee reproductive success. Nature, 561, 109-112.

Siviter, H., Koricheva, J., Brown, M.J.F. \& Leadbeater, E. (2018b) Quantifying the impact of pesticides on learning and memory in bees (ed M Pocock). Journal of Applied Ecology, 55, 2812-2821.

Sparks, T.C., Watson, G.B., Loso, M.R., Geng, C., Babcock, J.M. \& Thomas, J.D. (2013) Sulfoxaflor and the sulfoximine insecticides: Chemistry, mode of action and basis for efficacy on resistant insects. Pesticide Biochemistry and Physiology, 107, 1-7.

Stanley, D.A., Garratt, M.P.D., Wickens, J.B., Wickens, V.J., Potts, S.G. \& Raine, N.E. (2015a) Neonicotinoid pesticide exposure impairs crop pollination services provided by bumblebees. Nature, 528, 548-50.

Stanley, D.A., Smith, K.E. \& Raine, N.E. (2015b) Bumblebee learning and memory is impaired by chronic exposure to a neonicotinoid pesticide. Scientific Reports, 5, 16508.

Therneau, T.M. (2018) coxme: Mixed effects Cox models. R package version 2.2-7. URL https://cran.rproject.org/package=coxme

Tsvetkov, N., Samson-Robert, O., Sood, K., Patel, H.S., Malena, D.A., Gajiwala, P.H., Maciukiewicz, P., Fournier, V. \& Zayed, A. (2017) Chronic exposure to neonicotinoids reduces honey bee health near corn crops. Science, 356, 1395-1397.

United States Environmental Protection Agency. (2016) 2016 Addendum to the Environmental Fate and 
583

584

585

586

587

588

589

590

591

592

593

594

595

596

597

598

599

600

601

602

603

604

605

606

607

608

609

610

611

\section{Ecological Risk Assessment for Sulfoxaflor Registration.}

Whitehorn, P.R., O'Connor, S., Wackers, F.L. \& Goulson, D. (2012) Neonicotinoid pesticide reduces bumble bee colony growth and queen production. Science, 336, 351-352.

Wilkinson, A., Chan, H.-M. \& Hall, G. (2007) Spatial learning and memory in the tortoise (Geochelone carbonaria). Journal of Comparative Psychology, 121, 412-418.

Williams, P.H. \& Osborne, J.L. (2009) Bumblebee vulnerability and conservation world-wide. Apidologie, 40, 367-387.

Williamson, S.M., Baker, D.D. \& Wright, G.A. (2013) Acute exposure to a sublethal dose of imidacloprid and coumaphos enhances olfactory learning and memory in the honeybee Apis mellifera. Invertebrate Neuroscience, 13, 63-70.

Winfree, R., Aguilar, R., Vázquez, D.P., Lebuhn, G. \& Aizen, M.A. (2009) A meta-analysis of bees' responses to anthropogenic disturbance. Ecology, 90, 2068-2076.

Woodcock, B.A., Bullock, J.M., Shore, R.F., Heard, M.S., Pereira, M.G., Redhead, J., Ridding, L., Dean, H., Sleep, D., Henrys, P., Peyton, J., Hulmes, S., Hulmes, L., Sárospataki, M., Saure, C., Edwards, M., Genersch, E., Knäbe, S. \& Pywell, R.F. (2017) Country-specific effects of neonicotinoid pesticides on honey bees and wild bees. Science, 356, 1393-1395.

Woodcock, B.A., Isaac, N.J.B., Bullock, J.M., Roy, D.B., Garthwaite, D.G., Crowe, A. \& Pywell, R.F. (2016) Impacts of neonicotinoid use on longterm population changes in wild bees in England. Nature Communications, 7, 12459.

Wu, J.Y., Smart, M.D., Anelli, C.M. \& Sheppard, W.S. (2012) Honey bees (Apis mellifera) reared in brood combs containing high levels of pesticide residues exhibit increased susceptibility to Nosema (Microsporidia) infection. Journal of Invertebrate Pathology, 109, 326-329.

Zhang, E. \& Nieh, J.C. (2015) The neonicotinoid imidacloprid impairs honey bee aversive learning of simulated predation. Journal of Experimental Biology, 218, 3199-3205.

Zhu, Y., Loso, M.R., Watson, G.B., Sparks, T.C., Rogers, R.B., Huang, J.X., Gerwick, B.C., Babcock, J.M., Kelley, D., Hegde, V.B., Nugent, B.M., Renga, J.M., Denholm, I., Gorman, K., Deboer, G.J., Hasler, J., Meade, T. \& Thomas, J.D. (2011) Discovery and characterization of sulfoxaflor, a novel insecticide targeting sap-feeding pests. Journal of Agricultural and Food Chemistry, 59, 2950-2957.

Peer] reviewing PDF | (2019:03:35822:1:2:NEW 24 May 2019) 
Figure 1 (on next page)

Figure 1: Bumblebees olfactory learning

The performance of bumblebees in an olfactory learning task (a) the proportion ( \pm SEM) of bumblebees that learnt the olfactory association (b) the learning level ( \pm SEM) of the bees that did learn the association and (c) the trials in which bees learnt the association ( \pm SEM) in reference to trial number. (Control $n=23,2.4 p p b n=26,10 p p b n=24,250 p p b n=29$ ). 
Figure 2 (on next page)

Figure 2: Honeybee olfactory learning

The performance of honeybees in an olfactory learning task: (a) The proportion ( \pm SEM) of bumblebees that learnt the olfactory association (b) the learning level ( \pm SEM) of the bees that did learn the association (b) and (c) the trials in which bees learnt the association ( \pm $\mathrm{SEM}$ ) in reference to trial number. (Control $n=29,2.4 \mathrm{ppb} n=22,10 \mathrm{ppb} n=22,250 \mathrm{ppb} n=$ 21). 
Figure 3 (on next page)

Figure 3: Bumblebee and honeybee olfactory memory

The proportion of bumblebees and honeybees ( \pm SEM) responding to the conditioned stimuli 3 hours $(A \& B)$ and 24 hours $(C \& D)$ after training had finished. (Bumblebee $3 \mathrm{H}$, Control $n=$ 10, $2.4 \mathrm{ppb} n=12,10 \mathrm{ppb} n=11,250 \mathrm{ppb} n=17$; bumblebee $24 \mathrm{H}$ Control $n=9,2.4 \mathrm{ppb} n$ $=11,10 \mathrm{ppb} n=9,250 \mathrm{ppb} n=14$; Honeybee $3 \mathrm{H}$, Control $\mathrm{n}=28,2.4 \mathrm{ppb} n=21,10 \mathrm{ppb} n$ $=22,250 \mathrm{ppb} n=20$; honeybee $24 \mathrm{H}$ Control $\mathrm{n}=23,2.4 \mathrm{ppb} \mathrm{n}=13,10 \mathrm{ppb} \mathrm{n}=17,250 \mathrm{ppb}$ $n=16)$. 
Figure 4 (on next page)

Figure 4: Bumblebee performance on the radial arm maze:

(a) the total number of revisits ( $\pm \mathrm{SE}$ ) to already depleted landing platforms and, (b) the number of correct landing $( \pm S E)$ in the bees first 8 landings. 
A peerJ

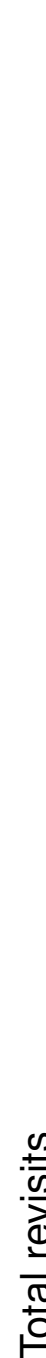

10

5

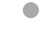

1

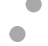

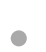

-

$0-1$
B

Manuscript to be reviewed
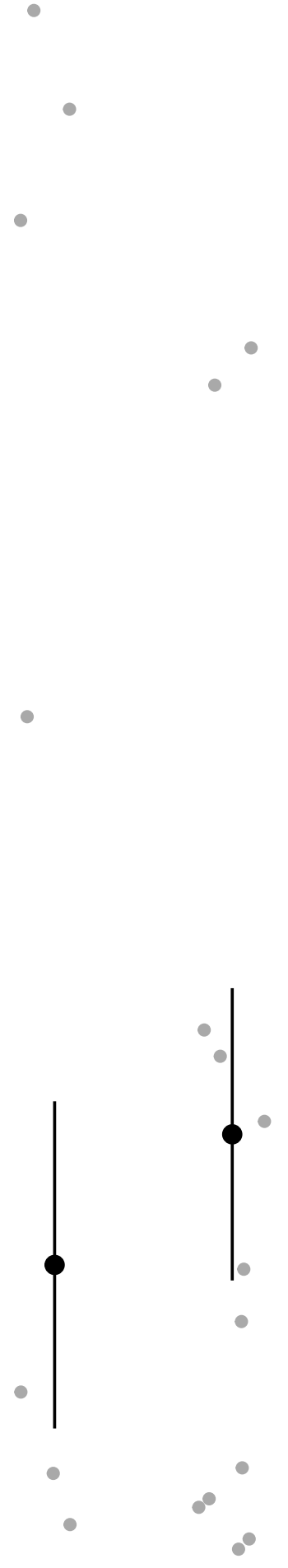

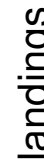

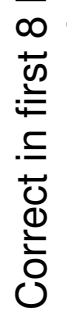

$\bullet$

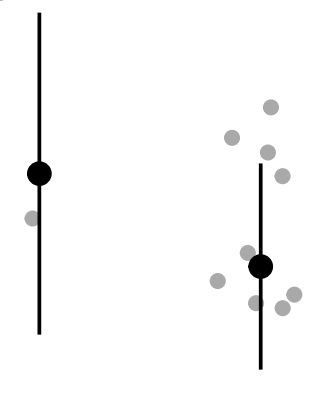

$\bullet$

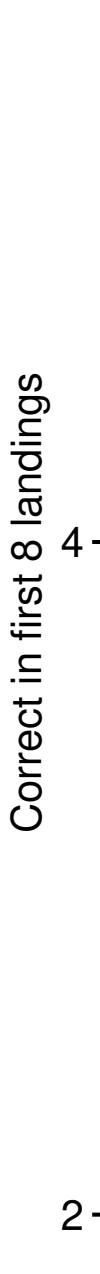

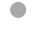

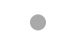
$4-$
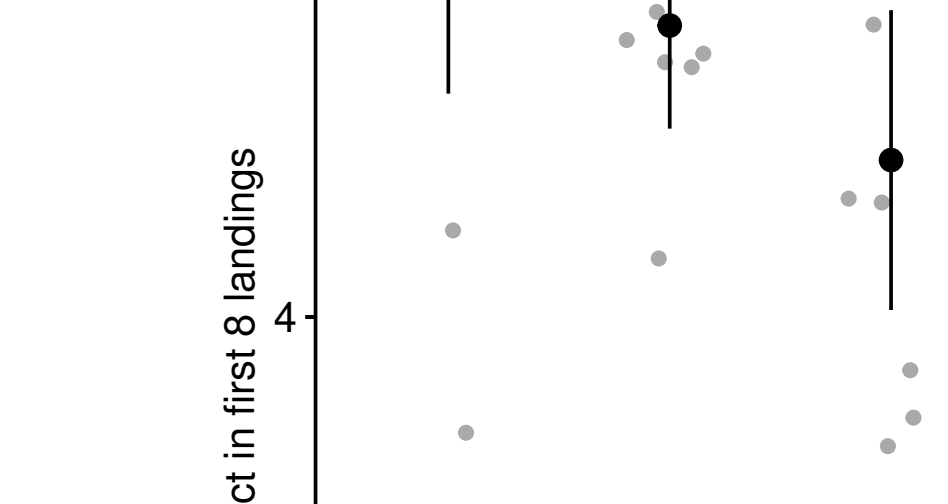

$\bullet$

$\bullet$
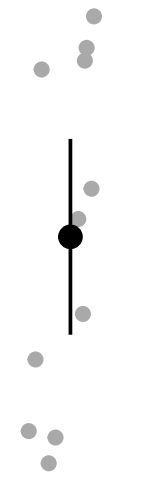

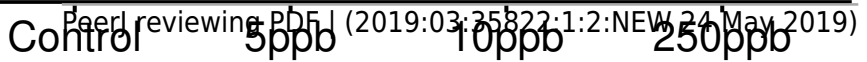

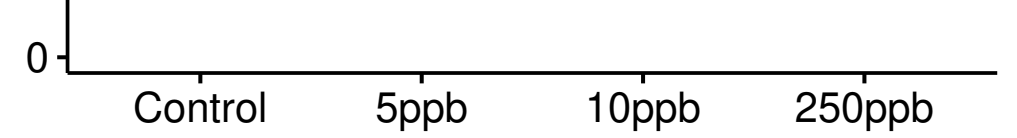


Figure $\mathbf{5}$ (on next page)

Figure 5: Kaplan-Meier curves of bees visiting landing platforms until a revist to an already delpeted resource occurs

$A=$ Control $(n=14), B=5 p p b(n=15), C=10 p p b(n=15)$ and $D=250 p p b(n=14)$. 
